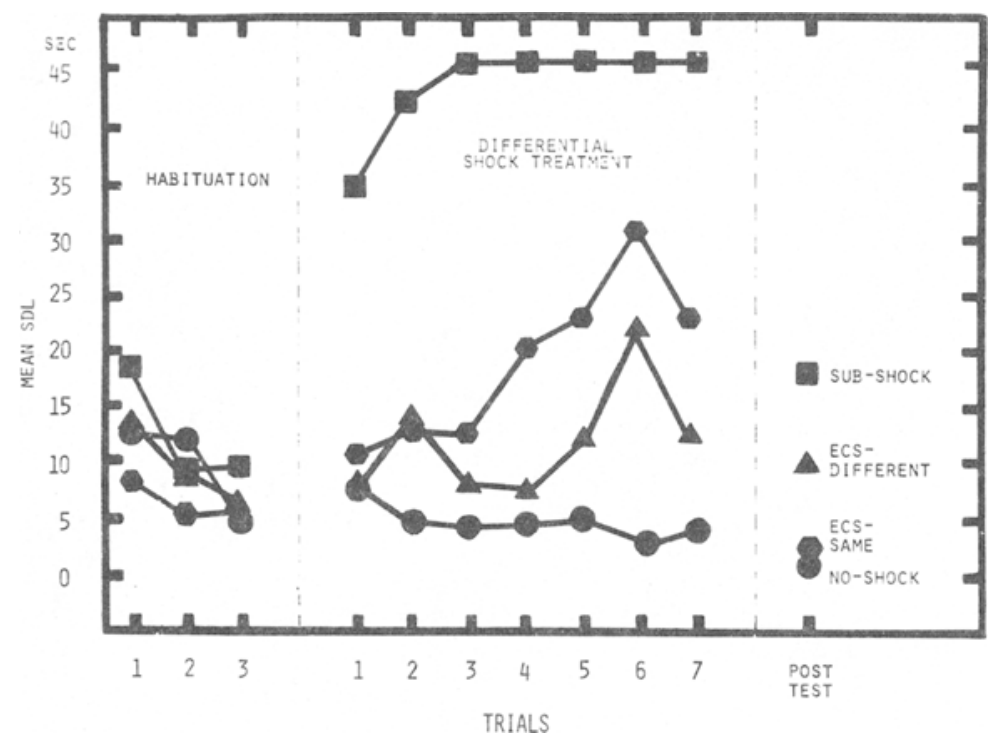

Fig. 1. Mean stepdown latency for each group on every trial.

for the subshock group and the means for both the no-shock and the ECS-same groups were significant $(p<.01)$

Two facts stand out. The first, that the posttest means for the ECS-different and the no-shock groups show no difference from the last trial of DST; and the second, that the sub-shock and ECS-same groups showed a marked decrease in SDLs on the posttest. These facts taken together indicate that the recovery compartment had a differential effect on the treatment group. The significance of this effect was tested by simple effects analysis for treatment groups. The analysis showed that the SDLs for the sub-shock and ECS-same groups decreased significantly $(\mathrm{F}=31.79, \quad \mathrm{df}=1 / 35$, $\mathrm{p}<.01$, and $\mathrm{F}=26.99, \quad \mathrm{df}=1.35$, $\mathrm{p}<.01$, respectively) in going from the last trial of DST to the posttest. The corresponding decreases in SDLs observed for the ECS-different and no-shock groups were not significant.

\section{DISCUSSION}

The finding of the present investigation, that avoidance developed differentially in the two ECS groups, suggests that some of this aversiveness is a function of the postshock recovery experience. Although SDLs increased in both ECS groups, they developed more slowly in the group recovering from ECS in the nonshock compartment. The fact that Ss in the ECS-different group showed little change in mean SDL in going from the final trial of the DST to the posttest, while the mean SDL for the ECS-same group was appreciably lowered, implied that components of this aversiveness due to recovery became associated, through principles of conditioning, with cues in the recovery environment.

Although the present results argue that part of the noxious effects of ECS are due to aspects of the recovery period, the fact that SDLs were observed to increase during DST warrants further consideration. In this respect it is useful to consider the possible contributions of stimulus generalization. Although intentions were to make the two recovery compartments as dissimilar as possible, at least one component, the stepdown platform, was the same in both cases. It was necessary to include this platform in Compartment B to obtain stimulus presentation.
Dember \& Earl (1957) suggest that Ss exposed to stimuli of varying complexity will demonstrate a preference for stimuli of "moderate complexity" and avoid stimuli which are either "extremely simple" or "extremely complex." This preference should result in an inverted U-shaped function, provided that the stimuli cover a sufficient range of complexity

avoidance measures on the posttest. Other possibilities might include kinesthetic cues involved in placing the animal on the platform. Stimulus generalization is evident in the performance of the subshock group on the posttest, where is appears that some aspects of the total experience in Compartment $B$ were similar enough to those in Compartment $A$ to result in significant avoidance.

In a similar manner, the finding that the aversive effects of ECS recovery become conditioned to stimuli in the recovery compartment can be extended to include stimulus generalization of cues in Compartment $B$ to cues in Compartment $\mathrm{A}$. This might then account for some of the avoidance behavior observed in the ECS-different group during the shock phase. Perhaps by making the experiences in the two compartments even less similar, the difference in SDLs between the two ECS groups could have been enhanced.

\section{REFERENCES}

CHOROVER, S. L., \& SCHILLER, P H. Short-term retrograde amnesia in rats. Joumal of Comparative \& Physiological Psychology, 1965, 59, 73-78.

DAWSON, R. G., \& PRIOR, G. T. Onset vs. recovery in the aversive effects of electroconvulsive shock. Psychonomic Science, 1965, 3, 273-274.

HUDSPETH, W. J. MIGAUGH, J. L., \& THOMSON, $C$. W. Aversive and amnesic effects of electroconvulsive shock. Joumal of Comparative \& Physiological Psychology, 1964, 57, 61-64.

McGAUGH, J, L." \& MADSEN, M. C. Amnesic and punishing effects of electroconvilsive shock. Science, 1964, $144,182-183$.

\section{NOTE}

1. Following the final trial of DST, one of the $\mathrm{Ss}$ in the ECS-different group expired, resulting in one less degree of freedom for all analysis which included the posttest.

\title{
Visual stimulus complexity and approach behavior in rats
}

\author{
J. DUTCH and L. B. BROWN \\ Victoria University of Wellington, Wellington, New Zealand
}

Three experiments examined the relationship between visual stimuli and approach behavior in rats. The results indicate that rats have an optimum preference level for stimulus complexity, which can be shifted by repeated

and include both ends of the continuum.

Several studies show that rats express a preference for the more complex of two stimuli (e.g., Dember, Earl, \& Paradise, 1957; Baker \& Franken, 1967). Recently, Sales (1968) has extended the findings in this area by presenting Ss with a wide range of complex stimuli, obtaining the predicted inverted $U$ function with 
Table 1

Percent Choosing the More Complex Stimulus, With Corresponding $p$ Values from the Binomial Test

\begin{tabular}{ccc}
\hline Trial & Percent & p \\
\hline 1 & 40.0 & .304 \\
2 & 53.3 & .500 \\
3 & 73.3 & .059 \\
4 & 46.6 & .500 \\
5 & 20.0 & .018 \\
\hline
\end{tabular}

Table 2

Percent Choosing the More Complex Stimulus, With Corresponding p Values from the Binomial Test

\begin{tabular}{ccc}
\hline Trial & Percent & p \\
\hline 1 & 50.0 & .623 \\
2 & 60.0 & .377 \\
3 & 80.0 & .055 \\
4 & 60.0 & .377 \\
5 & 40.0 & .377 \\
\hline
\end{tabular}

Table 3

Percent Choosing the More Complex Stimulus, With Corresponding p Values from the Binomial Test

\begin{tabular}{ccc}
\hline Trial & Percent & p \\
\hline 1 & 40.0 & .304 \\
2 & 73.3 & .059 \\
3 & 60.0 & .304 \\
4 & 60.0 & .304 \\
5 & 40.0 & .304 \\
\hline
\end{tabular}

an inspection-time measure but not with an approach measure. This raises a question of the behavior that would result from presenting stimuli in pairs and comparing levels of complexity that cover both ends of a simplicity-complexity continuum.

If stimuli are presented in pairs, the findings of Dember \& Earl (1957) would predict a tendency for rats to approach the stimulus that is closer to the optimum complexity level. Stimulus novelty also contributes to the choice (Berlyne \& Slater, 1957), but this can be controlled by giving each animal only one trial. Under these conditions it would be predicted that, when rats are to choose between pairs of stimuli which are below an optimum complexity level, the choice will be at random, while at the optimum level the more complex stimulus will be chosen and beyond that level the less complex will be chosen.

\section{EXPERIMENT 1} Method

The Ss were 75 experimentally naive male Sprague-Dawley rats from the Victoria University colony, aged between 100 and 120 days. They had been reared with their littermates in groups, and no pretraining or handling, beyond routine laboratory care, was given. Food and water were ad lib. The experimental apparatus was a hollow
"Y," made up of a startbox, $30 \mathrm{~cm}$ long, $15 \mathrm{~cm}$ wide, and $23 \mathrm{~cm}$ high, and two goalboxes, $38 \times 25 \times 23 \mathrm{~cm}$. All boxes were equipped with perspex covers and aluminum guillotine doors and were made of aluminum. The goalboxes were set at an angle to each other such that lines drawn from the center of the stimulus cards bisected a point $10 \mathrm{~cm}$ from the startbox door; the distance from the startbox door to the stimulus card was $1 \mathrm{~m}$. The area enclosed by the start- and goalboxes and the side walls thus formed a pentagon. The floor of the apparatus was covered with sawdust which was raked after each trial.

The experimental room was dark, except for two 2-W bulbs in each goalbox, wired behind $3-\mathrm{cm}$-wide aluminum strips placed on each side of each goalbox, which were also guides for the guillotine doors. No direct light was visible inside the pentagon, and the level of illumination on each card was $7 \mathrm{fL}$, while the level of illumination in the startbox was $0.113 \mathrm{fL}$. The stimulus cards were held in place by wooden frames and consisted of white cardboard rectangles $(23 \times 12.5 \mathrm{~cm})$ with vertical black stripes painted on them. The less complex stimulus in each pair was always a single vertical stripe. To control for brightness within each pair, the area of the single stripe was in each case equal to the total area of the several stripes on the more complex stimulus, in which each stripe was $0.5 \mathrm{~cm}$ wide and the distance between stripes was always $1.0 \mathrm{~cm}$. The more complex stimuli consisted of $2,4,6,8$, or 10 stripes, so that for the first comparison, the stimuli were one $1-\mathrm{cm}$ vertical stripe compared with two $0.5-\mathrm{cm}$ vertical stripes. There were 15 Ss randomly assigned to each comparison.

Each $S$ was taken to the experimental room and placed in the startbox; 1 min later the start door was raised. Trials were terminated when the $S$ was inside the goalbox and the door could be closed. Each $\mathrm{S}$ was given only one trial, and the position of the cards was randomized for each trial. No specific reward was given.

$$
\text { Results }
$$

The results are shown in Table 1.

\section{EXPERIMENT 2}

To extend the generality of this finding, a second experiment was conducted, using younger Ss. In other respects it was the same as Experiment 1 . Ss ranged in age from 60 to 80 days, and there were only 10 Ss in each group.

\section{Results}

The results of Experiment 2 can be seen in Table 2.

Overall, the results from Experiments 1 and 2 indicate that when novelty is held constant Ss tend to respond in terms of complexity. The results also indicate that the specific predictions about the stimulus approached were confirmed. One question which this finding raised is whether or not the peak of the inverted U-shaped function could be shifted. It is assumed that with repeated presentation to an $S$ a complex visual stimulus will lose some of its complex properties. It should therefore be possible to shift the complexity level of an $S$ by preexposure to the same or similar stimulus fields. Experiment 3 was designed to test this hypothesis.

$$
\text { EXPERIMENT } 3
$$

Experiment 3 differed from Experiment 1 in the following ways: Fifteen $\mathrm{Ss}$ were each given five trials, spaced on 5 successive days. The stimuli were presented in order of increasing complexity so that, for example, on Day $1 \mathrm{Ss}$ received the first comparison, and on Day 5 the fifth comparison.

\section{Results}

Table 3 shows the results of Experiment 3 .

The use of repeated trials reduced the complexity level with maximum effectiveness. It is apparent that the stimulus effects operate both between Ss with novelty controlled and within Ss. There is close agreement between the results of Experiment 3 and those obtained by Dutch (1969) with chicks in a similar situation.

\section{CONCLUSION}

The results of these three experiments support the hypothesis that the effects of increasing the complexity of visual stimuli produces behavior which conforms to an inverted U-shaped function, demonstrating an optimum level of stimulus complexity in the approach behavior of rats.

\section{REFERENCES}

BAKER, J. G.. \& FRANKEN, R. E Alternation as a function of drive level and visual complexity. Psychonomic Science, 1967, 8, 91-92.

BERLYNE, D. E., \& SLATER, J. Perceptual curiosity, exploratory behavior, and maze learning. Journal of Comparative \& Physiological Psychology, 1957, 50, 228-232.

DEMBER, W. N., \& EARL, R. W. Analysis of exploratory, manipulatory, and curiosity behaviors. Psychological Review, 1957,64, 91-96.

DEMBER, W. N., EARL, R. W.. \& PAR ADISE, $N$. Response by rats to differential stimulus complexity. Journal of Comparative \& Physiological Psychology, 1957, 50, 514-518.

DUTCH, J. Visual complexity and stimulus pacing in chicks. Quarterly Journal of Experimental Psychology, 1969, 21. 63-66.

SALES, S. M. Stimulus complexity as a determinant of approach behavior and inspection time in the hooded rat. Canadian Journal of Psychology, 1968 . 22, 11-17 